\title{
Cutting tools: finite element modeling of spark plasma sintering to improve their quality
}

\author{
Denis I. Yushin ${ }^{1, a}$, Andrey V. Smirnov ${ }^{1}$, Pavel Yu. Peretyagin ${ }^{1}$ \\ AND RAMON TORRECILLAS ${ }^{1,2}$ \\ 1 Moscow State University of Technology "STANKIN", 1 Vadkovsky per., 127994 Moscow GSP-4, Russian Federation \\ 2 Nanomaterials and Nanotechnology Research Center (CINN), Oviedo, Spain
}

Received 23 September 2015, Accepted 2 October 2015

\begin{abstract}
This article describes the numerical simulation of the spark plasma sintering (SPS) of the samples of alumina and tungsten carbide powders in the form of square plates with three different radii of curvature at the vertices of $0.8,1.2$ and $1.6 \mathrm{~mm}$. For each of the samples, the temperature distribution of mechanical stresses in the sample and in the mold was obtained. These results can be used to assess the theoretical possibility of sintering inserts by the SPS technology.
\end{abstract}

Key words: Spark-plasma sintering / modeling of physical processes / numerical modeling / finite element method / powder materials / alumina / tungsten carbide / producing of cutting plates

\section{Introduction}

Spark plasma sintering is one of the most progressive, promising, and dynamically developing methods of synthesis of composite materials and graded materials. This process has been studied in a number of works by various research groups $[1,2]$. The process of spark plasma sintering (SPS) is a joint action of high temperature (caused by Joule heating of the sintered material and molds), the axial pressure is up to $150-200 \mathrm{MPa}$, and DC pulse is of a large force (up to $20 \mathrm{kA}$ ) (see Fig. 1).

The main advantage of the SPS is the possibility of the synthesis of materials with the properties that were previously unavailable [3]. In addition, the SPS that allows the synthesis of the material is significantly faster than the use other methods of hot consolidation of powders. This is achieved by rapid heating of sintered powder when passing a pulsed direct current of great strength, and, presumably because of the formation of plasma in the areas of contact of the powder particles [2].

However, at present, wide application of the SPS process in industrial production is limited by the fact that the majority of products made along with this method have a cylindrical shape with the diameter ranging from 20 to $400 \mathrm{~mm}$ and the height less than $100 \mathrm{~mm}$. Obtaining the samples of nanocomposite powder materials of the specified shapes and sizes (near-net shape) by SPS is a very relevant and important scientific and technical

\footnotetext{
${ }^{a}$ Corresponding author: yushindenis@gmail.com
}

problem. This is due to the significant advantages of this technology when introducing it into the industrial production. The consolidation of samples of complex shape from powder materials by the SPS method is currently being studied in a number of works by research groups from different parts of the world [4]. The main difficulty of sintering samples of complex shape is to design special molds and technological processes of consolidation to obtain the desired homogeneity of the microstructure and, consequently, physical and mechanical properties of the sintered sample. Such tasks should be efficiently solved using the numerical simulation of sintering processes by the finite element method, as shown in a large number of publications by various authors [1-7].

However, it should be noted that the FEM analysis of the SPS process of samples in the form of cutting inserts has not been described in publications. In this paper, attempt is made with the help of FEM analysis to evaluate the possibility of obtaining samples in a form close to the square shape cutting plate by the SPS method.

\section{FEM modeling sintering of cutting plates}

In this study, numerical modeling was carried out by the finite element method process of the SPS of samples from powders of aluminum oxide and tungsten carbide in the form of square plates, similar replaceable indexable inserts standard geometry SNGN with a cutting edge length of $12 \mathrm{~mm}$ and with three different radii of the fillets at 


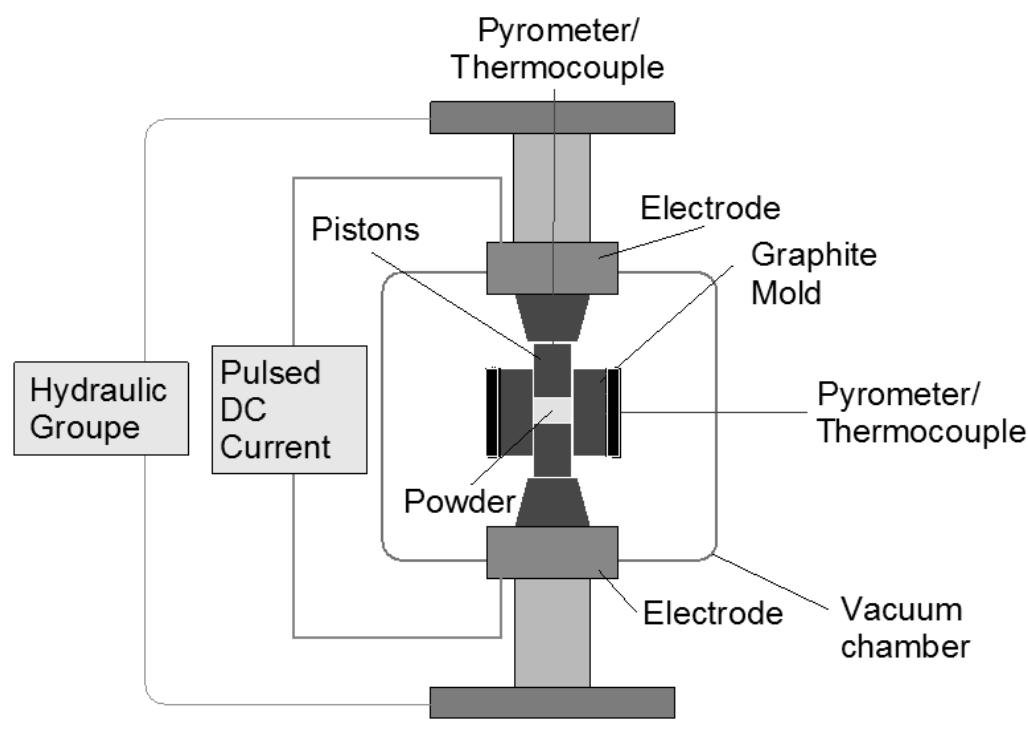

Fig. 1. Spark Plasma Sintering Diagram.

the top: $0.8,1.2$ and $1.6 \mathrm{~mm}$. For each of the samples, the temperature distribution and mechanical stresses in the sample and in the mold were obtained. These results can be used for the preliminary theoretical assessment of the possibility of sintering replaceable indexable cutting plates by the SPS method. Numerical modeling was performed using the software COMSOL Multiphysics.

Figure 2 shows the simplified configuration of the mold for sintering samples in the form of square replaceable indexable inserts. The properties of materials - graphite mold, pure aluminum oxide and tungsten carbide - were obtained from standard materials library of COMSOL Multiphysics software (see Table 1).

Numerical simulations were performed by solving the dual problem of thermo-electric and static loading in the COMSOL Multiphysics software. The thermo-electric task of heating the sample and the mold by means of application for $120 \mathrm{~s}$ of DC current $(8 \mathrm{kA}$ for alumina sample and $10 \mathrm{kA}$ for WC sample) was solved using a special module Joule heating. The task of modeling the stressstrain state of the system at the application of static loads to the upper punch size of $40 \mathrm{MPa}$ for $120 \mathrm{~s}$ was solved in the Solid Mechanics module of the COMSOL Multiphysics software.

\subsection{Modeling of temperature distribution in the sample and the mold}

Figure 3 shows the temperature distribution in a horizontal cross section of an alumina sample and graphite molds.

After analyzing the presented illustrations, one can see that the distribution of temperature fields during the sintering of the samples of aluminum oxide with different radii at the tops of the plates is identical in character

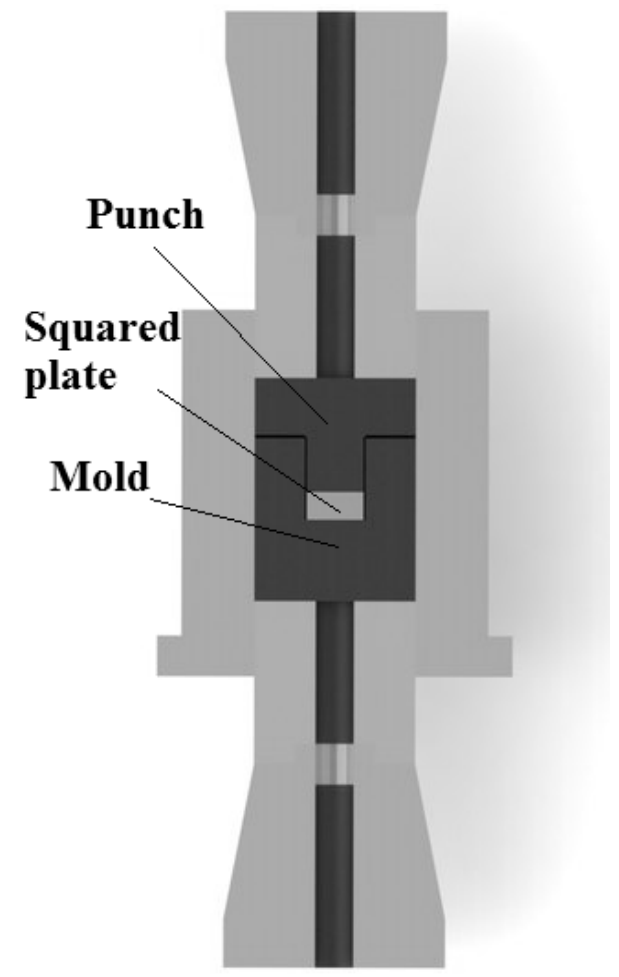

Fig. 2. The mold for sintering sample in the form of a square plate.

and in magnitude. The temperature gradient is directed from the center on the diagonal of the square cross section of the sample. The temperature difference in the cross section of the sample in all three models is in the range of $30-40{ }^{\circ} \mathrm{C}$. 
Table 1. Material properties.

\begin{tabular}{|c|c|c|c|c|c|c|}
\hline & $\begin{array}{l}\text { Electrical conductivity } \\
{[\mathrm{S} / \mathrm{m}]}\end{array}$ & $\begin{array}{l}\text { Heat capacity } \\
{[\mathrm{J} / \mathrm{kg} . \mathrm{K}]}\end{array}$ & $\begin{array}{l}\text { Thermal conductivity } \\
{[\mathrm{W} / \mathrm{m} . \mathrm{K}]}\end{array}$ & $\begin{array}{l}\text { Density } \\
{\left[\mathrm{kg} \cdot \mathrm{m}^{-3}\right]}\end{array}$ & $\begin{array}{l}\text { Young's modulus } \\
\text { [MPa] }\end{array}$ & $\begin{array}{l}\text { Poisson's } \\
\text { ratio }\end{array}$ \\
\hline Graphite & $3 \times 10^{3}$ & 710 & 150 & 1950 & $193 \times 10^{9}$ & 0.238 \\
\hline Alumina & 0 & 900 & 27 & 3900 & $300 \times 10^{9}$ & 0.222 \\
\hline Tungsten Carbide & $52 \times 10^{3}$ & 181 & 83 & 15770 & $710 \times 10^{9}$ & 0.234 \\
\hline
\end{tabular}

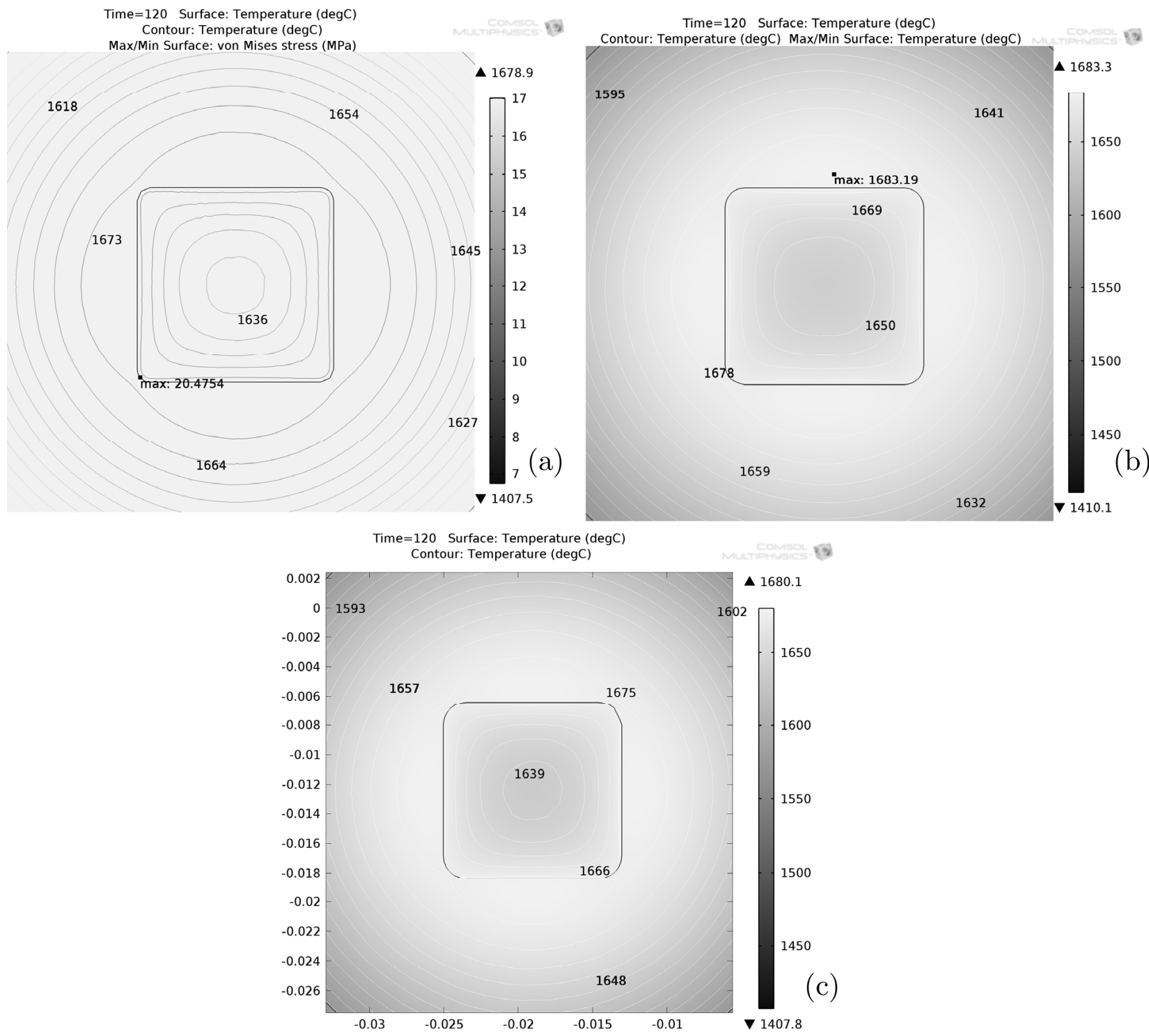

Fig. 3. Temperature distribution in a horizontal cross section of the system: the sample with corner radii of $0.8 \mathrm{~mm}$ (a), the sample with corner radii of $1.2 \mathrm{~mm}$ (b), the sample with corner radii of $1.6 \mathrm{~mm}$ (c). The sample material is $\mathrm{Al}_{2} \mathrm{O}_{3}$.

Figure 4 shows the distribution of temperature fields in a horizontal cross section of the mold at the level of the center sample of tungsten carbide.

The temperature change charts with a distance from the center of the system, consisting of a sintered sample and mold, were built in the direction of the diagonal of the square cross-section of the sintered sample (Fig. 5).

The form of the temperature distribution in the horizontal cross sections of the system mold - sample does not depend on the radius of the fillets at the vertices of the sample, and depends only on the material. Figure 6 shows the graphs of the variation of temperature with distance from the center of the sintered samples. The nature of the temperature gradients that occur in the volumes of the alumina samples (Fig. 6a) and tungsten carbide samples (Fig. 6b) is significantly different. When the sintering plate is made of electrically non-conductive material, the temperature increases from the center of the sample, and 


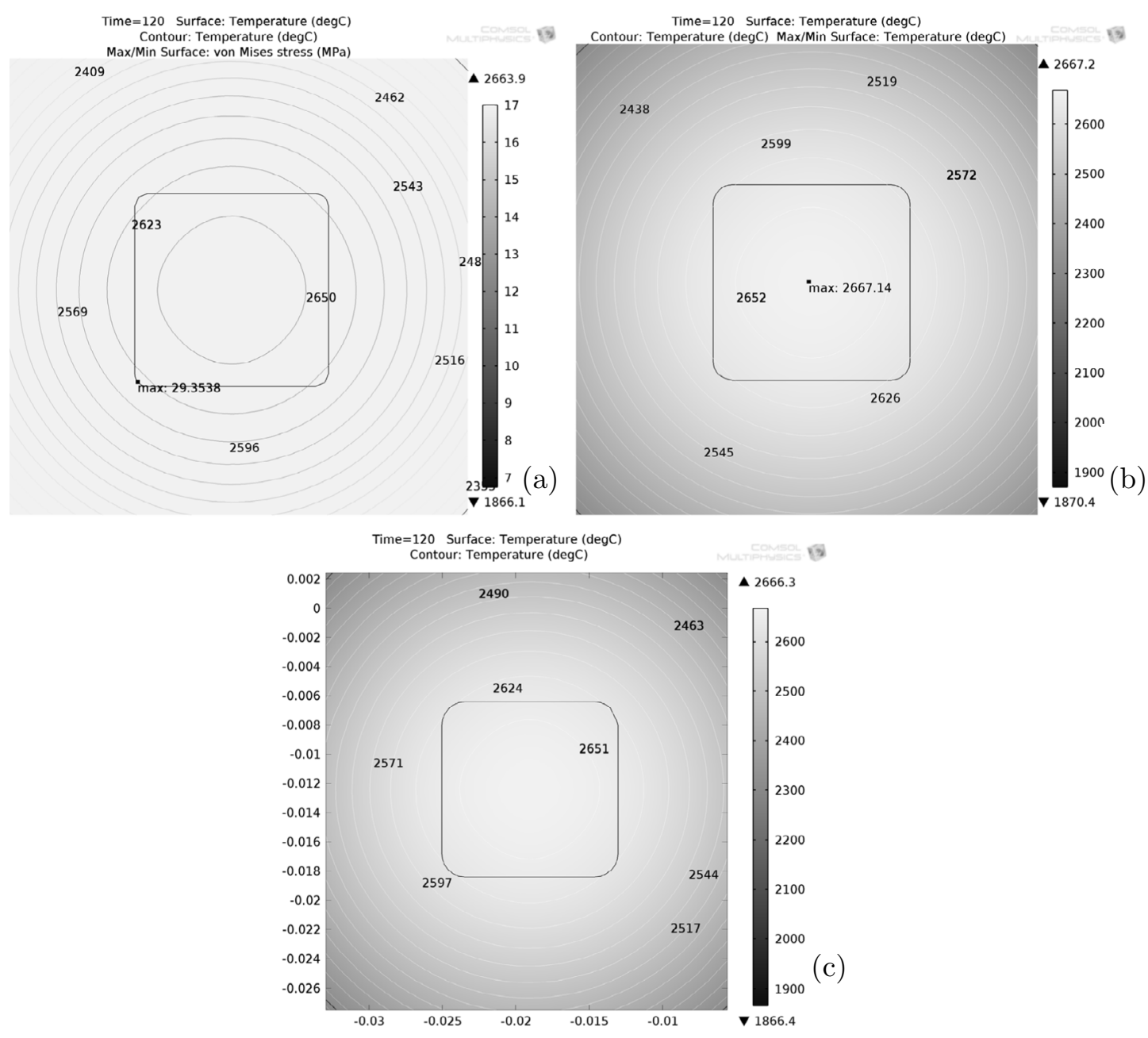

Fig. 4. Temperature distribution in a horizontal cross section of the system: the sample with corner radii of $0.8 \mathrm{~mm}$ (a), the sample with corner radii of $1.2 \mathrm{~mm}$ (b), the sample with corner radii of $1.6 \mathrm{~mm}$ (c). The sample material is WC.

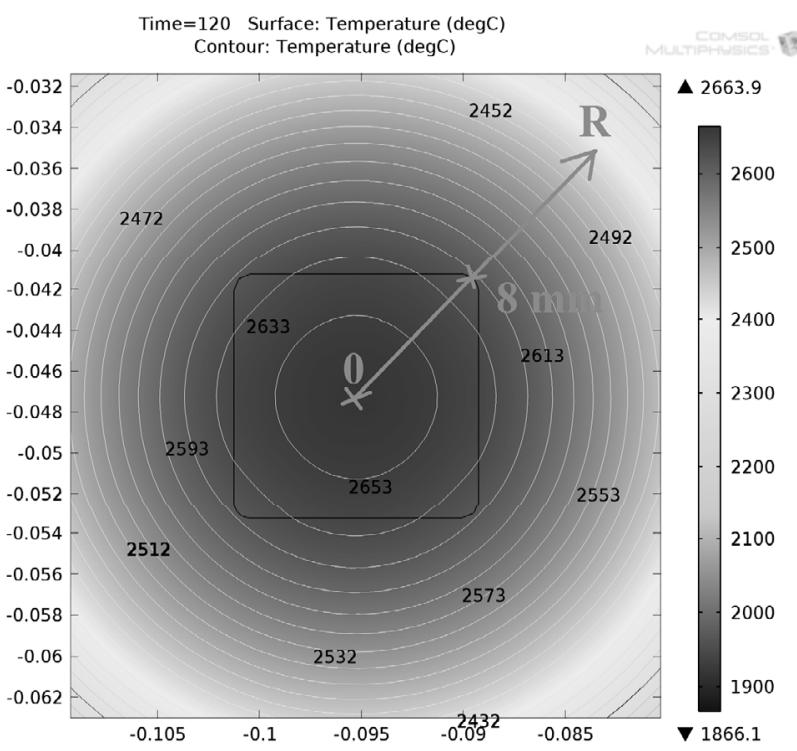

Fig. 5. Radial direction in the horizontal section of the system used for creating profiles. when the sintering plates are made of conducting material, on the contrary, maximum temperature is reached in the center of the sample.

\subsection{Modeling of the distribution of mechanical stresses in the sample and the mold}

Figure 7 shows the distribution of mechanical stresses in the horizontal section of the specimen and the mold during sintering plates made of alumina. Figure 8 shows similar illustration of the modeling of the sintering process of a plate made of tungsten carbide. The point of greatest interest is the magnitude of stresses in the graphite punches near the sample, namely in the vicinity of the corners as the corners of the mold are stress concentrators.

The distribution of mechanical stresses, which can be traced in the above Figures 7 and 8, leads to the conclusion that, regardless of the material of sintered samples, the greatest mechanical stresses occur during sintering inserts with corner radii of $0.8 \mathrm{~mm}$. However, the magnitude of the mechanical stresses in the graphite punch 

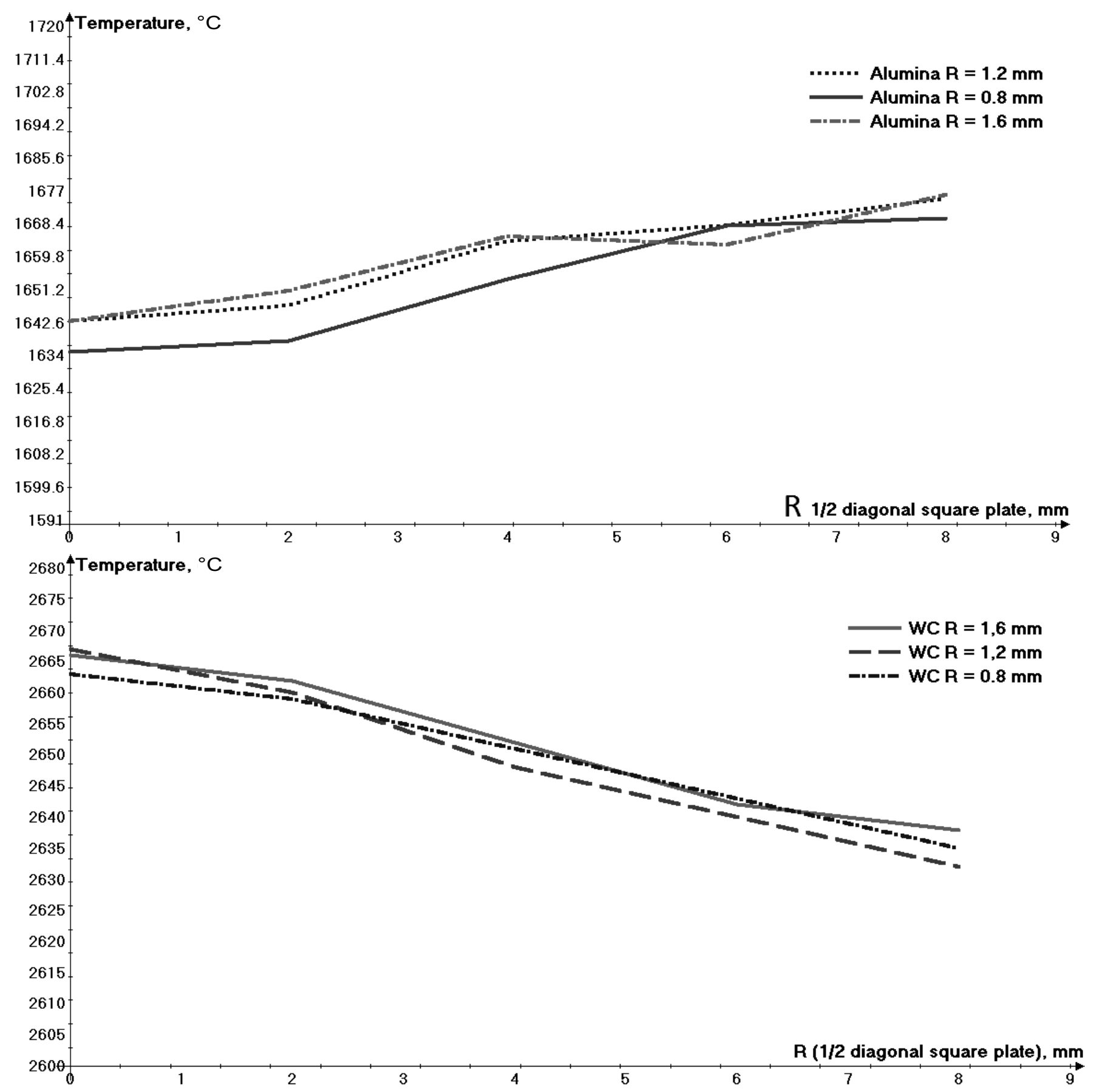

Fig. 6. Profiles of temperature change in horizontal section of the sintered samples: (a) inserts made of alumina, (b) inserts made of tungsten carbide.

near the stress concentrator does not exceed $21 \mathrm{MPa}$ at a sintering plate made of alumina (Fig. 9a), and does not exceed $30 \mathrm{MPa}$ in the case of sintering of a plate made of tungsten carbide powder (Fig. 9b). This means that in case of the samples sintered of the powders of alumina and tungsten carbide in the form of polyhedral disposable plates with radii at the vertices of $0.8,1.2$ and $1.6 \mathrm{~mm}$, it is possible to use one-part graphite punches.

\section{Discussion}

There are no significant differences in the size or the character during the distribution of temperature fields when sintering the samples made of aluminum oxide with various radii at the vertices of plates by the SPS method. The temperature gradient is directed diagonally from the center of the square section of the sample. Temperature differences in the sample's section in three models are 


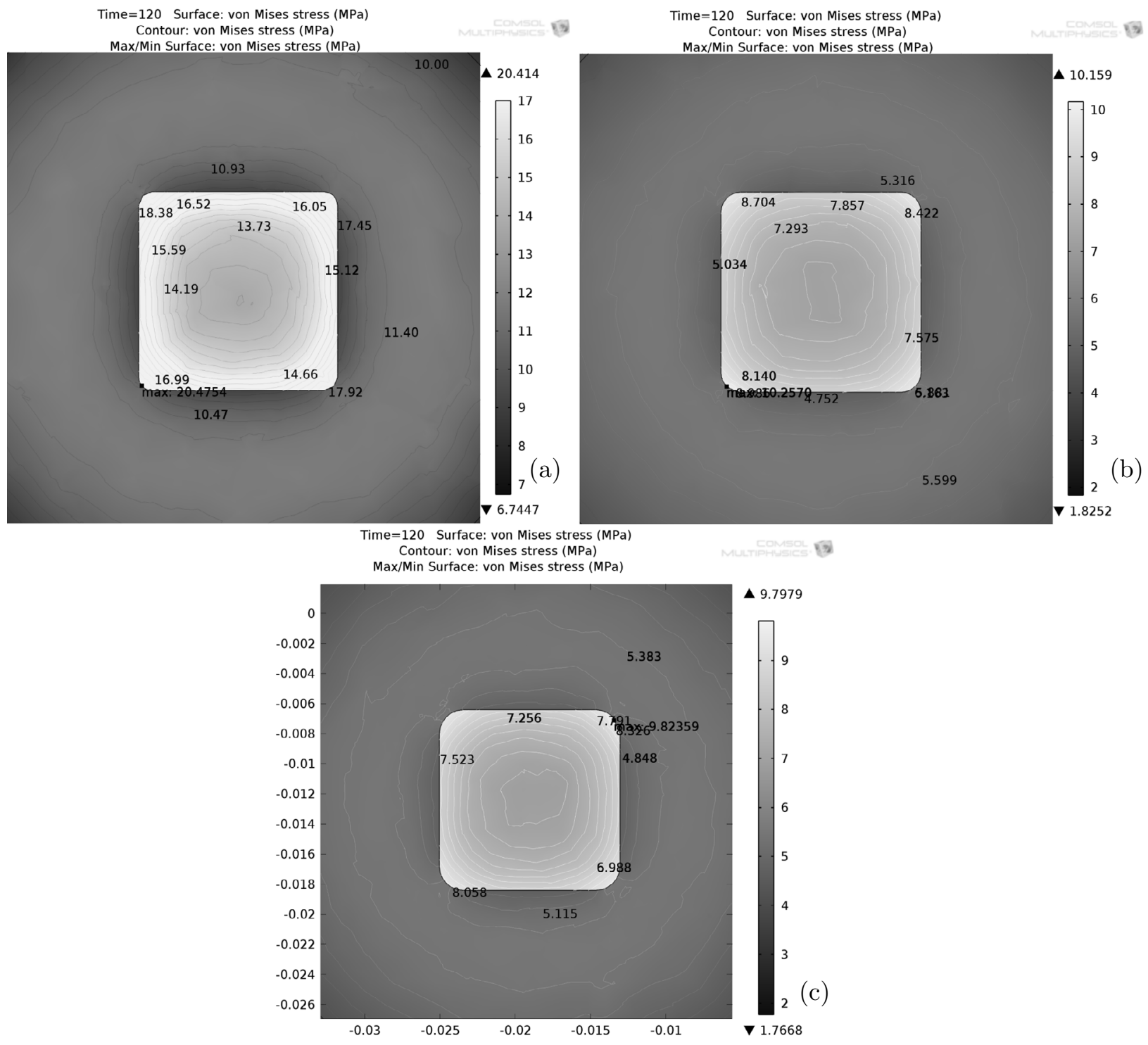

Fig. 7. Stress distribution in the horizontal cross section of the system: the sample with corner radii of $0.8 \mathrm{~mm}$ (a), the sample with corner radii of $1.2 \mathrm{~mm}$ (b), the sample with corner radii of $1.6 \mathrm{~mm}$ (c). The sample material is $\mathrm{Al}_{2} \mathrm{O}_{3}$.

$30-40{ }^{\circ} \mathrm{C}$. This temperature gradient for such a small sample can be considered significant which negatively influences the homogeneity of physical-mechanical properties in the volume of a sintered plate [7]. There are several methods for equalizing the temperature field: the extended hold at a maximum temperature during the sintering process; the application of a matrix of other shapes and sizes or made of other material (not graphite) [3]; the application of hybrid heating, i.e. additional heating induction element providing additional heating for the press tool [2].

Regardless the material of the sintered sample, the most significant mechanical stresses take place when sintering the plate with radii at the vertices of $0.8 \mathrm{~mm}$. However, the values of mechanical stresses in graphite plug near the spherical radius at the sample's vertex in the shape of square plate do not exceed $21 \mathrm{MPa}$ during sintering the plate made of aluminum oxide (Fig. 9a), and do not exceed $30 \mathrm{MPa}$ during the consolidation from tungsten carbide powder (Fig. 9b). It means that in case of sintering the samples made of aluminum oxide and tungsten carbide powders in the shape of multifaceted disposable plate with radii at the vertices of $0.8,1.2$ and $1.6 \mathrm{~mm}$ it is possible to use one-part graphite punches of complex shape, as the limit of graphite's strength used for the production of press tools for SPS, is within the range of 50-100 $\mathrm{MPa}$, depending on the type of graphite.

\section{Conclusions}

According to the analysis of the results obtained due to the finite element modeling of spark-plasma sintering of the samples made of aluminum oxide and tungsten carbide powders in the shape of square plates with cutting 


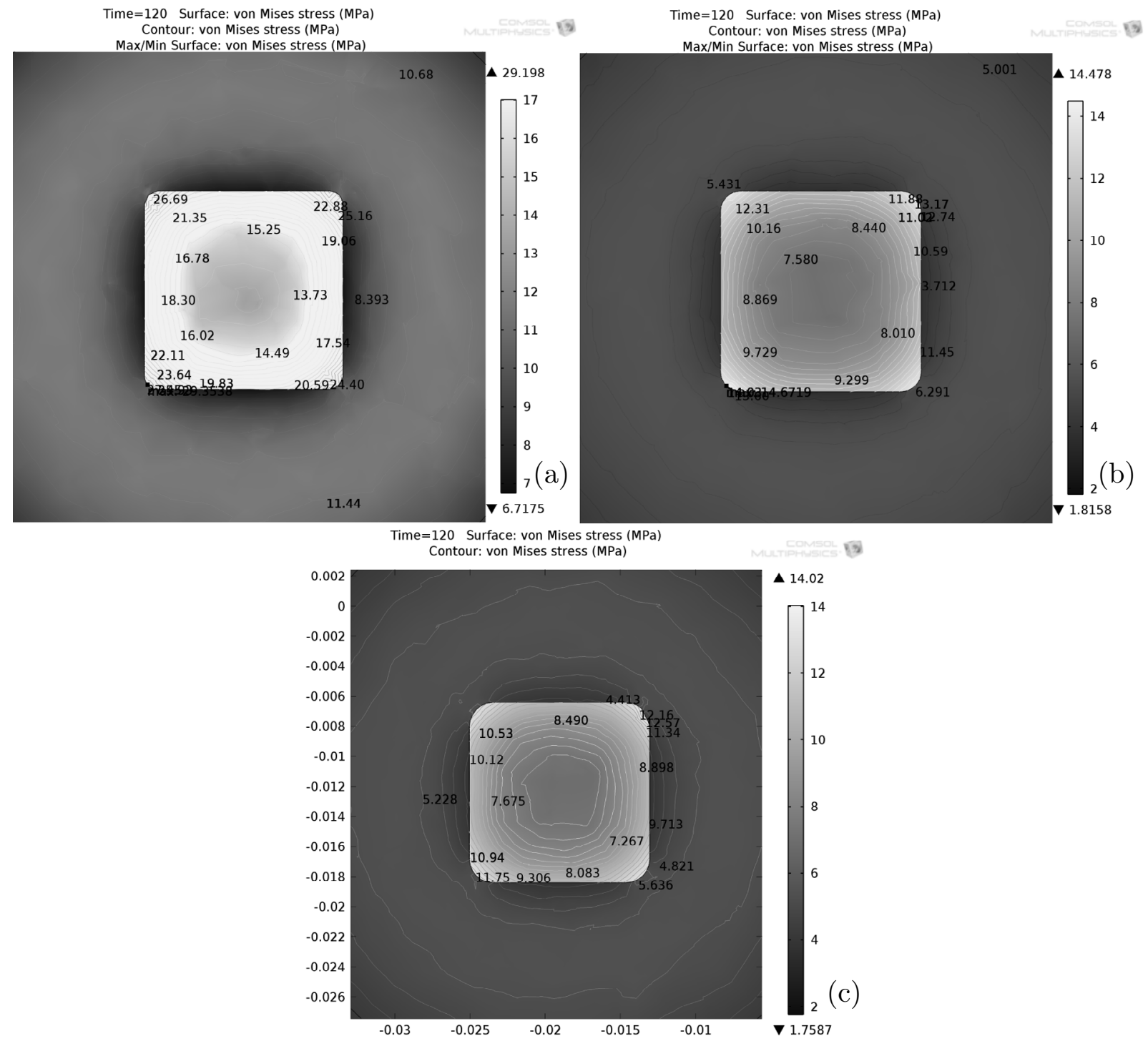

Fig. 8. Stress distribution in the horizontal cross section of the system: the sample with corner radii of $0.8 \mathrm{~mm}$ (a), the sample with corner radii of $1.2 \mathrm{~mm}$ (b), the sample with corner radii of $1.6 \mathrm{~mm}$ (c). The sample material is WC.

edge of $12 \mathrm{~mm}$ and three various spherical radii at the vertices of $0.8,1.2$ and $1.6 \mathrm{~mm}$, following conclusions have been made. There are no significant differences in the size or the character during the distribution of the temperature fields when sintering the samples in the shape of square plate with various radii at the vertices for each material. The most significant temperature gradients are directed from the center diagonally in the samples made of aluminum oxide, and, oppositely, close to the center in tungsten carbide plates, the temperature differences in the samples sections are within the range of $30-40{ }^{\circ} \mathrm{C}$. This temperature gradient for such small samples is significant which negatively influences the homogeneity of physical-mechanical properties. There are several methods for equalizing temperature field: the extended hold at a maximum temperature during sintering process; the application of a matrix of different shape and sizes, or made of different material (not graphite); using the technology with hybrid heating. Regardless of the material of the sintered samples, the most significant mechanical stresses take place during the sintering of the plate with radii at the vertices of $0.8 \mathrm{~mm}$. However, the values of mechanical stresses in the graphite punch near spherical radius at the sample's vertex in the shape of square plate do not exceed $21 \mathrm{MPa}$ during sintering the plate made of aluminum oxide, and do not exceed $30 \mathrm{MPa}$ during the consolidation from tungsten carbide powder. For the sintering of the samples made of aluminum oxide and tungsten carbide powders in the shape of multifaceted disposable plate with radii at the vertices of $0.8,1.2$ and $1.6 \mathrm{~mm}$ it is possible to use one-part graphite punches of complex shape, as the limit of graphite's strength used for the production of press tools for SPS, is within the range of 50-100 MPa, depending on the graphite type. 


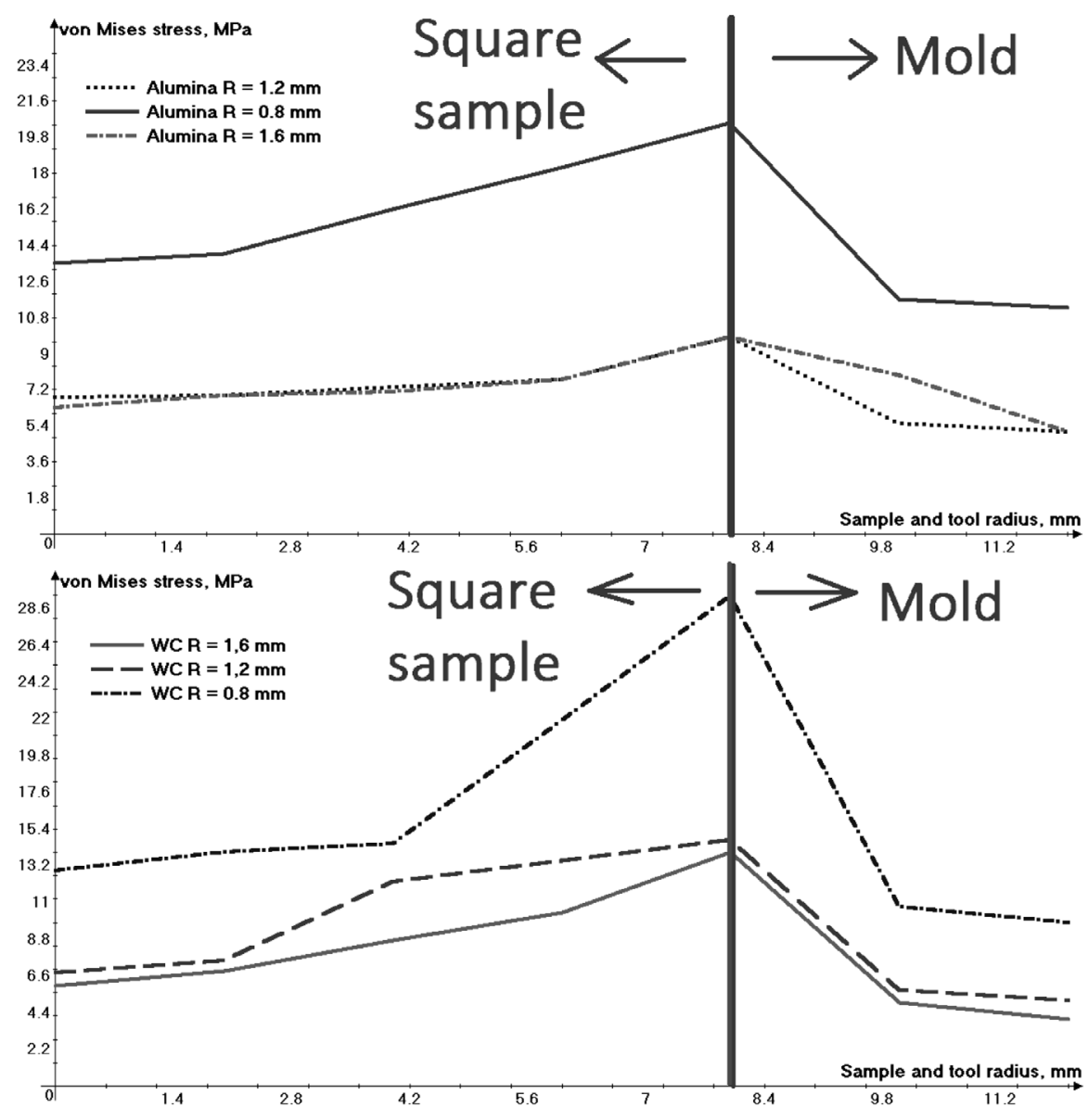

Fig. 9. Graphs of the mechanical stresses in the horizontal section of sintered samples: inserts made of alumina (a), inserts made of tungsten carbide (b).

Acknowledgements. The work was performed within the framework of the Resolution of The Government of the Russian federation dated 9 April 2010 No. 220 "On the measures taken to attract the key scientists to Russian educational institutions providing higher professional education, scientific establishments of state academies of science and state scientific centers of the Russian Federation" (Agreement No. 14.B25.31.0012 dated June 26, 2013).

\section{References}

[1] U. Anselmi-Tamburini, S. Gennari, J.E. Garay, Z.A. Munir, Fundamental investigations on the spark plasma sintering/synthesis process, Mater. Sci. Eng. A 394 (2005) 139-148

[2] M. Suárez, A. Fernández, J.L. Menéndez, R. Torrecillas, H.U. Kessel, J. Hennicke, R. Kirchner, T. Kessel, Challenges and Opportunities for Spark Plasma Sintering: A Key Technology for a New Generation of Materials/Sintering Applications, edited by Burcu Ertuğ, I InTech, Chapters published February 06, 2013 under CC BY 3.0 license, 350 p.
[3] O. Guillon, J. Gonzalez-Julian, B. Dargatz, T. Kessel, G. Schierning, J. Rathel, M. Herrmann, FieldAssisted Sintering Technology/Spark Plasma Sintering: Mechanisms, Materials, and Technology Developments, Adv. Eng. Mater. 16 (2014) 830-849

[4] T. Voisina, L. Duranda, N. Karnataka, S.L. Galletc, M. Thomas, Y. Le Berree, J.F. Castagnef, A. Coureta, Temperature control during Spark Plasma Sintering and application to up-scaling and complex shaping, J. Mater. Process. Technol. 213 (2013) 269-278

[5] K. Vanmeensel, A. Laptev, J. Hennicke, J. Vleugels, O. Van der Biest, Modelling of the temperature distribution during field assisted sintering, Acta Mater. 53 (2005) $4379-4388$

[6] K. Vanmeensel, A. Laptev, O. Van der Biest, J. Vleugels, Field assisted sintering of electro-conductive $\mathrm{ZrO} 2$-based composites, J. Eur. Ceram. Soc. 27 (2007) 979-985

[7] C. Wang, L. Cheng, Zh. Zhao, FEM analysis of the temperature and stress distribution in spark plasma sintering: Modelling and experimental validation, Comput. Mater. Sci. 49 (2010) 351-362 